\title{
EFFECTIVE LEARNING IN TECHNOLOGICAL EDUCATION
}

\author{
G. Ivanov*, A. Kalinova \\ Faculty of Educatioan, Trakia University, Stara Zagora, Bulgaria
}

\begin{abstract}
Objective of the study is to support the work of the teacher to overcome the difficulties in learning in technological training.

Object of study - training home life and equipment 1 - 4 grade and subject - methodical solutions for effective learning.

On the basis of its exploration activity suggest methodological solutions for effective learning in the context of changes in social development. With examples illustrate the practical possibilities for implementing these decisions. We believe that the presented methodological solutions are not only possible, but a step towards the realization of subject-subjective relations in education and achieving effective learning.
\end{abstract}

Key words: technological training, learning, subject-subjective relations, methodological decisions, entrepreneurship

\section{TIMELINESS OF PROBLEM}

In his book "How Children Fail" John Holt tells children and adults who do not use their minds well. Moreover, the author also deals with people who do the opposite, teaching boldly and effectively. According to Holt, „children learn best age before they start school and primary grades“. (2, 8p.) Many experts accept that argument, although each granting it for different reasons.

In this article we offer methodological solutions for effective learning for students of primary school age. A more detailed look at learning in teaching home life and equipment. And this is not accidental, because the basis of our methodological solutions for effective learning on the understanding that learning is not just a perception and memorizing certain volume scientific information and learning which allow for full expression of the students. Both processes of "absorption" and "expression" more important for students of this age is the second. This is one reason why learning in teaching this course can be seen on two levels - first - as an opportunity for personal expression of the student and the second - as an opportunity for socialization of

${ }^{*}$ Correspondence to: Prof. Georgi Ivanov, Trakia University, Faculty of Educatioan, Bulgaria,georgiiv@mail.bg students in the context of changes in social development.

In this article we look at learning in its didactic aspects and is affecting issues related to perception, understanding, strengthening and implementation into practice, the psychological aspects of these processes are not the subject of our attention.

Primary teachers often ask how to approach training to enable all students to cope with planned activities. And their worries are justified, because there students who can meet the cognitive and practical activities to acquire new learning content. Along with them there are other - not only difficult digest this content, but starting a particular cognitive activity, difficulties and refuse from further activity. In such cases, the teacher calls "Work, do not be distracted!" "Think!" Proved futile. We should not forget that "students are learning attitudes they want to succeed, to meet the expectations of the teacher, to be noticed, praised, encouraged, to gain recognition for their efforts". (7, 23 p.) They have a desire to succeed, but there are difficulties discourage them. These difficulties are the subject of our attention and overcoming them is a guideline to search for methodological solutions.

The first type of difficulties faced by students, stem from the contradiction between their 
dominant type of thinking and verbalization learning. On the one hand students have the attitude to actively explore the world around them, curious in various forms - to see, to touch, to try to do, and learning are forced to act as recipients of verbal information. The desire to get to know the student as manipulate real objects, examines them, compare them with known objects, change their shape, to seek practical solutions to the problem by combining and test their properties until the desired line is faced with the imperatives "Watch out!", "Do not talk!" "Listen!", "Repeat", "Remember!", "works without disturbing other". As a result of the implementation of these imperatives, the student becomes a good performer. Preoccupation of this artist is to obtain recognition of teacher for their obedience. It is natural to ask: To what is directed schooling obedience Is its main purpose ?; For social development only good performers needed ?; Calls for transformation of the student in a subject in training, and with it and subject to its knowledge and development, are not doomed to failure?

The answers show themselves.

The second type of difficulties determining ineffective learning are related to the contradiction between the teacher the opportunity to work with all students frontally - on the one hand and on the other - the need to carry out pedagogical interaction with each student. "Class-classroom level system suggests a form of training, which provided educational content is presented to all students and it must be mastered by everyone. There is no doubt that this can not be achieved for several reasons, the most important among which are the individual psychological characteristics of students - cognitive abilities, temperament, dominant type of thinking, attitudes to learning, learning conditions outside training and more". (6, 34 p.)

This submitted controversy and the ensuing difficulties for effective learning outline pessimistic outlook for schooling. Yet there are opportunities to overcome these difficulties.

\section{OPPORTUNITIES TO OVERCOME THE DIFFICULTIES IN TRAINING}

The first option is associated with a change in the educational content. It should be done in such a way that it gives a chance for the success of students with different cognitive and practical abilities, including students with special educational needs. Educational content should be considered as a unity of information gets verbal and time information, the absorption becomes a specific practical basis.
It is therefore essential in training to be able to differentiate the activities. This differentiation allows each student to choose an action to occur. It is logical to assume that this requirement will affect the volume of educational content on any topic from the textbook - have educational content for students with different readiness to deal with cognitive and practical activities. And then this educational content will be positioned as in previous books - two pages - the left and right (solution), and will cover many more pages. Our proposed solution is not associated with an increase in the volume of pages in the textbook. It is connected with the possibility of developing new educational content in the context of a specific practical activity - making a device with varying degrees of completion. In this approach, students can make an independent choice of activity and have the freedom to implement it in accordance with their idea of success - build (functional characteristics of the finished product).

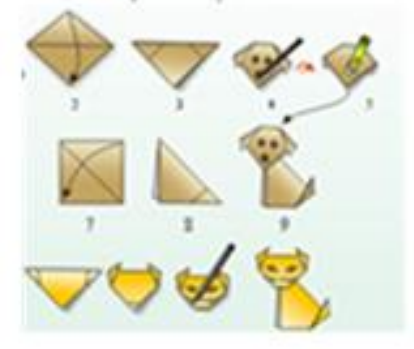

\section{Models of various fairy tale characters, obtained by the same method of folding.}

For example in the implementation of training on the topic "Theatre table" students are given the opportunity to choose the model of the fairy-tale character who will participate in the dramatization of some or fairy tale. The choice of model of a different character (in this case a dog or cat) does not imply specific explanation and demonstration, as well as various recipes for both products because the technology in their construction is the same - the same method of folding, but in a different direction.

The second opportunity to overcome the aforementioned difficulties associated with the natural attitude of the student to know the world through its active conversion. For this purpose, the training conditions are created to get to know the student as manipulate real objects, including examines them to compare their properties with the properties of known objects, change their shape, to seek practical solutions to the problem by combining them to test new features, converts them to the desired result. The first step in this direction is Vol. 13, Suppl. 1, 2015 
connected with the creation of attitude for success. This means working with students so as to achieve a smooth transition from externally motivated activity to inner conviction a manifestation of activity - striving for personal expression, to experience the joy of success and satisfaction achieved. It is hardly necessary to explain how important the attitude of students that will succeed. Indicative of this is the parable of the elephant from the circus, which despite its size and strength, stands tied with very thin chain stuck a peg in the ground. The slightest effort of the elephant would be enough to break the chain, although thread, but he does not do this because at a very early age he was tethered with a robust chain driven deep into the ground stake. How has tormented the little elephant to release, how many attempts the rule, how many times is reaching exhaustion, but ... chain and stake insurmountable obstacle to his freedom. It is this chain and this stake driven into the ground have affected his attitude that can not get rid of them. And later he became great and mighty elephant with any thin chain bound him, he was already sure that he can be released.

The situation is similar with the students in learning - if you fail several times to cope with the activities if they fail to overcome the difficulties they are discouraged and form attitudes that will never succeed, they are outsiders, there is no point even try. It is known that the sample making attempts to deal with a task is a very important element in training. This is precisely why a second step towards success in learning is to ensure conditions disciple to seek solutions by testing different options. For example, on the topic "Do try and watch" students are given the opportunity to experimentally determine what qualities paper is best suited for making boat origami.

Third possibility to overcome the difficulties in teaching home life and technique is on providing conditions for creativity.

Creativity, analyzed from the perspective of the elderly and the position of young students is different. "Adults considered to be a manifestation of creativity everything leads to the creation of something new, unknown to humanity so far - the creation of a new objective". (8, 68 p.) An example of a creative solution is the construction of a cycle path coverage, which generates electricity from the sun. When students creativity taken every effort to achieve a result different from the model - something with better features of the model. In the case of creative activity of students is not necessarily linked to the creation of a new objective and the creation of something new in the context of cognitive and practical abilities of students - creating new subjective. In this connection, creativity can be achieved in the implementation of various activities in education, for example:

When choosing the most suitable material for making a device - what material to produce a bird feeder so that it is resistant to weathering;

When choosing a technology for producing product - what sequence of technological operations will follow in drawing up the model of race car - first stick the spoilers and then the wheels or first wheels, spoilers and then (no access for sticking spoilers if glued wheels);

- When choosing the organization of the activity - in teamwork, in what order will be produced and assembled in the individual general construction details;

In determining the functional characteristics of the finished product - what else could use crafted article if you bring certain changes in the structure (reconstruction - Christmas bells in a basket, etc.);

- $\quad$ In finding the most suitable structure to solve a given technical problem - what structure to use for making a bird feeder so The food does not get wet from rain or snow;

In determining the impact that will have the use of certain materials for production of an article or on the manufactured product breaking branches needed to develop a product of natural materials, herbs roots, decorate the classroom with cut tree;

In seeking opportunities to achieve originality, uniqueness - aesthetic shape made product - the use of different colors, different shapes, different designs, different functionality to achieve different effects;

- $\quad$ In seeking opportunities for achieving full similarity between working patterns and real object - complement the model with elements that make it easily recognizable or those that highlight specific functions (model roller have items which highlight the possibilities for its use in different conditions in the dark - lights, strong sunlight - cabin, limited visibility - mirrors, smoke from the engine - high exhaust).

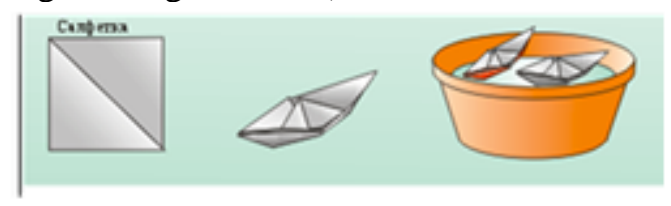

Establishing quality paper empirically 


\section{METHODOLOGICAL SOLUTIONS}

Implementation of training in home life and equipment, leading to socialization of students in the context of changes in social development is still sporadic. On the one hand society sets out the principles of the market economy and the resulting views to nurture the entrepreneurial spirit from the school bench, the other - in the school the student is not a subject in training. It is not clear how pupils will nurture entrepreneurial spirit and will generate entrepreneurial skills, then it does not create conditions for them to show personal initiative, responsibility, ability to make independent decisions, including take and justify the risk. Or put another way, if school student is not subject to training, he could not be a subject for future professional appearance. In connection with this offer several methodological solutions whose application in education would help to achieve the subjectsubjective relations (student - operator training), namely:

First. Providing opportunities for student choice - choice in the curriculum of: technology, organization of activities, performance of the manufactured product, its application, etc .; choice of educational content related to cognitive and practical capabilities (a student with a normal rate of movement in the resolution of cognitive and practical tasks; disciple, ahead in development; student retarded or one with special educational needs).

Second. Providing every student to operate independently to achieve the set objectives (the selection).

Third. Providing every student selfassessment activities and its results in terms of selected targets (desired outcome).

\section{IVANOV G., et al.}

Fourth. Enabling the students of amendment in open discrepancy between obtained and the desired result.

Fifth. Enabling the student to determine future activities and actions to achieve selfdetermined goals.

Sixth. Inclusion in the curriculum of activities that the student is experiencing its "I" level: "I do," "I try," "I manage," "I understand," "I create."

\section{CONCLUSION}

The proposed methodological solutions are not exclusive. But they are a step towards effective learning and create opportunities for the realization of subject-subjective relations in teaching home life and equipment.

\section{REFERENCES}

1. Andreev, M. (2001) Learning process. Didactics. Sofia.

2. Holt, John. (1964) How Children Fail.

3. Vasilev, D. (1992) Pedagogy. University edition. Sofia

4. Vasileva E. (2002) Child in elementary school. Sofia

5. Ivanov, G., E. Vasileva (2012) Fundamentals of Primary School Education. Stara Zagora.

6. Ivanov, G. (2008) Pedagogical interaction in technological preparation of children from 3 to 11 years. Stara Zagora.

7. Ivanov, G. (2008) Employment skills of small pupil. Stara Zagora.

8. Ivanov, G. (2008) Multi-sensing in technical and technological training. Stara Zagora.

9. Maslow, E. (2002). Motivation and personality. Publishing House Prosveta. Sofia. 